\title{
STATISTICAL PROCESS CONTROL (SPC) UNTUK PENGENDALIAN KUALITAS PRODUK MEBEL DI UD. IHTIAR JAYA
}

\author{
R. Elyas ${ }^{1}$ dan W. Handayani $\left.{ }^{\star}\right)^{2}$ \\ Jurusan Manajemen, Universitas Pembangunan Nasional Veteran Jawa Timur \\ E-mail: wiwik.em@upnjatim.ac.id
}

\begin{abstract}
Abstrak
Pengaruh globalisasi di dunia industri saat ini telah menyebabkan persaingan yang ketat dan kompetitif antara perusahaan. UD. Ihtiar Jaya adalah perusahaan manufaktur yang bergerak di bidang furnitur, terutama yang terbuat dari kayu jati. Perusahaan melayani penjualan produk ritel, serta melayani atau merenovasi berbagai jenis furnitur. Untuk dapat menghasilkan kualitas yang baik, kegiatan pengendalian kualitas dilakukan. Penelitian ini bertujuan untuk mengetahui jumlah produk furnitur yang cacat dan jenis cacat yang paling dominan di UD. Ihtiar Jaya, untuk menganalisis implementasi kontrol kualitas di UD. Jaya Jaya menggunakan Pengendalian Proses Statistik dalam upaya mengurangi jumlah produk yang rusak, dan untuk mengidentifikasi faktor-faktor apa yang menyebabkan kerusakan / cacat pada produk yang diproduksi oleh UD. Ihtiar Jaya. Penelitian ini, sampel yang digunakan adalah jumlah cacat pada produk furnitur di UD. Ihtiar Jaya pada tahun 2018. Teknik penentuan sampel ini menggunakan purposive sampling. Penelitian ini menggunakan metode Pengendalian Proses Statistik, yaitu check sheet, diagram pareto, diagram kendali, dan diagram tulang ikan.

Berdasarkan hasil check sheet, disimpulkan bahwa rata-rata cacat produk adalah 10,38\% per bulan. Dari hasil diagram Pareto dapat diketahui bahwa tingkat cacat tertinggi adalah tergores dengan total 104 unit atau $61,18 \%$ dari total produk cacat pada tahun 2018. Sedangkan hasil bagan kontrol yang telah dibuat dapat dilihat bahwa kontrol kualitas tidak terkontrol dan tidak sesuai dengan standar. Dari hasil diagram tulang ikan disimpulkan bahwa faktor yang menyebabkan cacat produk adalah faktor manusia, mesin produksi, bahan, metode kerja, dan lingkungan kerja.
\end{abstract}

Kata kunci: Kontrol Kualitas, Cacat, Kontrol Proses Statistik, Lembar Periksa, Pareto, Control Chart, dan Diagram Fishbone

\section{Abstract}

The influence of globalization in the industrial world today has led to intense and competitive competition between companies. UD. Ihtiar Jaya is a manufacturing company engaged in furniture, especially those made from teak wood. The company serves retail product sales, as well as servicing or renovating various types of furniture. To be able to produce good quality, quality control activities are carried out. This research aims to determine the number of defective furniture products and the most dominant type of defects at UD. Ihtiar Jaya, to analyze the implementation of quality control at UD. Jaya Jaya uses Statistical Process Control in an effort to reduce the number of defective products, and to identify what factors cause damage/defects in products manufactured by UD. Ihtiar Jaya. In this research, the sample used was the number of defects in furniture products at UD. Ihtiar Jaya in 2018. The technique of determining this sample uses purposive sampling. This research uses the Statistical Process Control method, namely check sheet, pareto diagram, control chart, and fishbone diagram.

Based on the results of the check sheet, it was concluded that the average product defect was $10.38 \%$ per month. From the results of the Pareto diagram can be seen that the highest level of defects is scratched with a total of 104 units or $61.18 \%$ of the total defective products in 2018 . While the results of the control chart that have been made can be seen that the quality control is not controlled and not in accordance with standards. From the results of fishbone diagram concluded that the factors that cause product defects are human factors, production machinery, materials, work methods, and work environment.

Keywords: Quality Control, Defects, Statistical Process Control, Check Sheet, Pareto, ControlChart, and Fishbone Diagram 


\section{Pendahuluan}

Pengaruh globalisasi di dunia industri saat ini telah menyebabkan persaingan yang ketat dan kompetitif antar perusahaan.Kemampuan perusahaan dalam memenuhi kebutuhan pelanggan merupakan suatu hal yang sangat penting dalam persaingan (Elmas, 2016). Industri mebel (furniture) merupakan industri yang mengolah bahan baku atau bahan setengah jadi kayu, rotan, dan bahan alami lainnya menjadi produk barang jadi yang bisa disebut dengan mebel (furniture) yang mempunyai nilai tambah dan manfaat yang lebih tinggi (Salim dan Munadi, 2017). Agar perusahaan dapat bertahan hidup dan memperoleh kemajuan di bidang usahanya, perusahaan harus mengelola usahanya dengan baik dan menghasilkan produk dengan kualitas bagus dan terjamin.Maka dari itu perusahaan harus mengadakan kegiatan pengendalian kualitas yaitu aktivitas memantau suatu produk, baik barang maupun jasa agar dapat memenuhi kebutuhan konsumen sesuai standar yang telah ditetapkan (Trenggonowati dan Arafiany, 2018). Pengendalian kualitas yang dilaksanakan dengan baik akan memberi kan dampak terhadap kualitas produk yang dihasilkan oleh perusahaan. Standar kualitas meliputi bahan baku, proses produksi dan produk jadi (Nasution, 2010). Oleh karenanya, kegiatan pengendalian kualitas tersebut dapat dilakukan mulai dari bahan baku, selama proses produksi berlangsung sampai pada produk akhir dan disesuaikan dengan standar yang tetapkan.

Intiar Jaya adalah sebuah perusahaan manufaktur yang bergerak di bidang mebel (furniture), khususnya yang berbahan kayu jati.Perusahaan ini melayani penjualan produk secara retail, dan juga servis atau renovasi berbagai jenis mebel. Kegiatan pengendalian kualitas mempunyai tujuan ganda yakni untuk memperoleh kualitas produk yang sesuai dengan standar kualitas perusahaan dan sesuai dengan harapan konsumen, sehingga menjamin pangsa pasar dan kelangsunga $n$ hidup perusahaan. Ihtiar Jaya selalu berupaya untuk menjaga kualitas produk mebelnya dengan melaksanakan proses produksi sebaik mungkin hingga sampai ke tangan konsumennya. Namun selama ini ternyata kegiatan produksi masih banyak mengal ami kecacatan seperti mebel yang lecet, penyok, tidak simetris, dan warna belang. Hal ini menyebabkan adanya produk yang rusak dan tidak sesuai dengan standar kualitas yang diharapkan sehingga Ihtiar Jaya harus mengendalikan tingkat kerusakan agar tidak sampai ke tangan konsumen.Berikut merupakan data jumlah produksi dan jumlah kecacatan produksi mebel UD. Ihtiar Jaya pada tahun 2018:

Tabel 1.Data Produksi Mebel di UD. Ihtiar Jaya pada Tahun 2018

\begin{tabular}{clccc}
\hline No & \multicolumn{1}{c}{ Bulan } & $\begin{array}{c}\text { Jumlah Produksi } \\
\text { (unit) }\end{array}$ & $\begin{array}{c}\text { Jumlah Kecacatan } \\
\text { (unit) }\end{array}$ & $\begin{array}{c}\text { Jumlah Produk } \\
\text { Layak (unit) }\end{array}$ \\
\hline 1 & Januari & 210 & 22 & 188 \\
2 & Februari & 76 & 10 & 66 \\
3 & Maret & 100 & 12 & 88 \\
4 & April & 364 & 18 & 346 \\
5 & Mei & 124 & 10 & 114 \\
6 & Juni & 94 & 12 & 82 \\
7 & Juli & 146 & 16 & 130 \\
8 & Agustus & 206 & 16 & 190 \\
9 & September & 166 & 16 & 150 \\
10 & Oktober & 106 & 19 & 96 \\
11 & November & 150 & 12 & 138 \\
12 & Desember & 92 & 16 & 76 \\
\hline \multicolumn{7}{r}{ Jumlah } & 1834 & 179 & 1664 \\
\hline
\end{tabular}

Dari Tabel 1 dapat dilihat bahwa jumlah kecacatan produk mebel yang terjadi cukup tinggi setiap bulannya pada tahun 2018. Dari total produksi sebanyak 1834 uni terdapat 170 unit yang mengalami kecacatan, sehingga hanya 1664 unit saja yang layak untuk sampai ke tangan konsumen. Hal ini merupakan kerugian bagi perusahaan karena perusahaan harus mengeluarkan biaya pengendalian untuk memperbaiki kerusakan tersebut. Selain itu, pesanan produk mebel yang harus diantar kepada konsumen menjadi terhambat dan tidak 
tepat waktu karena proses perbaikan tersebut. Statistical Processing Control merupakan sebuah teknik statistik yang digunakan secara luas untuk memastikan bahwa proses memenuhi standar. Selain Statistical Processing Control merupakan sebuah proses yang digunakan untuk mengawasi standar, Statistical Processing Control juga membuat pengukuran dan mengambil tindakan perbaikan selagi sebuah produk atau jasa sedang diproduksi (Heizer dan Render, 2015).

Pada penelitian ini yang akan diteliti adalah kecacatan yang mungkin terjadi pada setiap bagian proses produksi pada produk mebel jati perusahaan Ihtiar Jaya. Objek penelitian tidak terfokus pada satu jenis barang saja, karena Ihtiar Jaya tidak memproduksi barang dalam jumlah besar, beberapa barang juga dibuat berdasarkan pesanan, sehingga penelitian tidak bisa terfokus pada satu jenis produk saja. Pengertian pengendalian kualitas menurut pendapat beberapa ahli yaitu sebagai berikut: Pengendalian kualitas adalah suatu kegiatan yang sangat perlu dilakukan oleh setiap kegiatan produksi.Hal ini disebabkan kualitas atau mutu barang dan jasa hasil produksi perusahaan itu merupakan cermi $\mathrm{n}$ keberhasilan perusahaan dimata masyarakat atau konsumen didalam melakukan usaha produksinya. (Gitosudarmo, 2014)

Pengertian pengendalian kualitas menurut pendapat Handoko (2012) merupakan upaya mengurangi kerugian-kerugian akibat produk rusak dan banyaknya sisa produk atau scrap. Sedangkan menurut Gasperz (2010), pengendalian kualitas adalah teknik dan aktivitas operasional yang digunakan untuk memenuhi standar kualitas yang diharapkan. Tujuan pengendalian kualitas adalah: 1) Mengurangi kesalahan dan meningkatkan mutu. 2) Mengilhami kerja tim yang baik. 3) Mendorong keterlibatan dalam tugas. 4) Meningkatkan motivasi para karyawan. 5) Menciptakan kemampuan memecahkan masalah. 6) Menimbulkan sikap-sikap memecahkan masalah. 7). Memperbaiki komunikasi dan mengembangkan hubungan antara manager dengan karyawan.8) Mengembangkan kesadaran akan konsumen yang tinggi. 9). Memajukan karyawan dan mengembangkan kepemimpinan. 10). Mendorong penghematan biaya. Pengendalian kualitas harus dapat mengarahkan beberapa tujuan terpadu, sehingga konsumen dapat puas menggunakan produk, baik barang atau jasa perusahaan. Beberapa hal yang perlu mendapat perhatian agar tujuan dapat tercapai, antara lain: 1) Ada standar yang ditetapkan 2). Menentukanpenilaian terhadap hasil pekerjaan yang telah dilaksanakan dengan standar yang ada. 3). Memberikan penjelasan yang sejelas-jelasnya kepada pihak-pihak yang bersangkutan agar tidak terjadi salah paham. Montgomery (2012) dan berdasarkan beberapa literatur lain menyebutkan bahwa faktor-faktor yang mempengaruhi pengendalian kualitas yang dilakukan perusahaan adalah: 1) Kemampuan proses, Batas-batas yang ingin dicapai haruslah disesuaikan dengan kemampuan proses yang ada. Tidak ada gunanya mengendalikan suatu proses dalam batas-batas yang melebihi kemampuan atau kesanggupan proses yang ada. 2). Spesifikasi yang berlaku, spesifikasi hasil produksi yang ingin dicapai harus dapat berlaku, bila ditinjau dari segi kemampuan proses dan keinginan atau kebutuhan konsumen yang ingin dicapai dari hasil produksi tersebut. Dalam hal ini haruslah dapat dipastikan dahulu apakah spesifikasi tersebut dapat berlaku dari kedua segi yang telah disebutkan di atas sebelum pengendalian kualitas pada proses dapat dimulai. 3) Tingkat ketidaksesuaian yang dapat diterima, Tujuan dilakukan pengendalian suatu proses adalah dapat mengurangi produk yang berada di bawah standar seminimal mungki $n$. Tingkat pengendalian yang diberlakukan tergantung pada banyaknya produk yang berada di bawah standar yang dapat diterima. 4). Biaya kualitas, biaya kualitas sangat mempengaruhi tingkat pengendalian kualitas dalam menghasilkan produk dimana biaya kualitas mempunyai hubungan yang positif dengan terciptanya produk yang berkualitas.

Tujuh alat pengendalian kualitas yang digunakan untuk mengidentifikasikan dan menganalisis masalah-masalah kualitas yang sedang dihadapi agar masalah tersebut dapat dikendalikan sebagaimana disebutkan oleh Heizer dan Render (2015), antara lain: 1) Diagram Pareto (Pareto Diagram) Pareto Diagram adalah bagan yang berisikan diagram batang dan diagram garis; diagram batang memperlihatkan klasifikasi dan nilai data, sedangkan diagram garis mewakili total data kumulatif. Klasifikasi data diurutkan dari kiri ke kanan menurut urutan ranking tertinggi hingga terendah.Ranking tertinggi merupakan 
masalah prioritas atau masalah yang terpenting untuk segera diselesaikan, sedangkan ranking terendah merupakan masalah yang tidak harus segera diselesaikan (Heizer and Render, 2015). 2) Diagram Sebab Akibat (Cause and EffectDiagram) Diagram sebabakibat adalah suatu diagram yang menggambarkan garis dan simbol-simbol yang menunjukan hubungan antara penyebab dan akibat suatu masalah, untuk selanjutnya diambil tindakan perbaikan atas masalah tersebut (Besterfield, 2013). 3). Lembar Periksa (Check Sheet) Check Sheet adalah suatu formuli $r$ berupa item-item yang akan diperiksa telah dicetak dalam formulir dengan maksud agar data dapat dikumpulkan secara mudah dan ringkas (Montgomery, 2012) 4).Peta Kendali (Control Chart) Control chart atau peta kendali adalah peta yang digunakan untuk mempelajari bagaimana proses perubahan dari waktu ke waktu (Besterfield, 2013). Data di-plot dalam urutan waktu. Control chart selalu terdiri dari tiga garis horisontal, yaitu: Garis pusat (center line), garis yang menunjukkan nilai tengah (mean) atau nilai rata-rata dari karakteristik kualitas yang di-plot-kan pada peta kendali. Upper control limit (UCL), garis di atasgaris pusat yang menunjukkan batas kendali atas. Lower control limit (LCL), garis dibawah garis pusat yang menunjukka $n$ batas kendali bawah.

\section{Metode}

Obyek penelitian adalah PT Ihtiar Jaya. Teknik pengambilan sampel dalam penelitian ini menggunakan teknik purposivesampling.Purposive Sampling merupakansuatu teknik penentuan sampel berdasarkan atas pertimbangan tertentu (Sugiyono, 2015). Selanjutnya sampel yang digunakan dalam penelitian ini adalah: Produk mebel dengan jenis cacat ringan berupa mebel yang lecet dan mebel yang penyok di UD. Ihtiar Jaya pada tahun 2018. Produk mebel dengan jenis cacat berat berupa mebel yang tidak simetris dan mebel dengan warna belang di UD. Ihtiar Jaya pada tahun 2018.

Penelitian ini menggunakan jenis data primer dan data sekunder.Data primer yaitu data primer berupa hasil wawancara, survey, maupun observasi pada objek penelitian. Sedangkan data sekunder yaitu berupa bukti, catatan atau laporan historis yang telah tersusun dalam arsip (data dokumen) yang dipublikasikan dan tidak dipublikasikan Adapun data-data tersebut sebagai berikut: 1) Data Kuantitatif, data yang dapat diinput ke dalam skala pengukuran statistik. Fakta dan fenomena dalam data ini tidak dinyatakan dalam bahasa alami, melainkan dalam numerik. 2) Data Kualitatif, data yang dapat mencakup hampir semua data non-numerik.Data ini dapat menggunakan kata-kata untuk menggambarkan fakta dan fenomena yang diamati. Dalam penelitian ini, analisis data dilakukan dengan menggunakan beberapa alat dari Seven Tools di dalam metode SPC (Statistical Process Control).

Langkah-langkahnya adalah sebagai berikut: 1) Membuat Check Sheet, data yang diperoleh dari perusahaan terutama data produksi dan data produk rusak kemudian diolah menjadi tabel Check Sheet secara rapi dan terstruktur. Hal ini dilakukan agar memudahkan dalam memahami data tersebut hingga bisa dilakukan analisis lebih lanjut. 2) Membuat Diagram Pareto, setelah diketahui data jenis kerusakan pada produk dan jumlah frekuensinya di dalam Check Sheet, maka langkah selanjutnya yaitu membuat diagram pareto. Hal ini dapat membantu menemukan permasalahan terpenting untuk segera diselesaikan sampai dengan yang tidak harus segera diselesaikan. 3) Membuat Peta Kendali $P$ (P-chart) dalam menganalisis data penelitian ini,digunakan peta kendali $p$ (peta kendali proporsi kerusakan) sebagai alat untukpengendalian proses secara statistik. Penggunaan peta kendali $p$ ini dikarenakan pengendalian kualitas yang dilakukan bersifat atribut, serta data yang diperolehyang dijadikan sampel pengamatan tidak tetap dan produk yang mengalami kerusakan tersebut dapat diperbaiki lagi sehingga harus ditolak (reject). 4) Membuat Diagram Sebab Akibat (Fishbone Diagram) setelah diketahui masalah utama yang paling dominan, maka dilakukan analisafaktor kerusakan produk dengan menggunakan fishbone diagram, sehingga dapat menganalisa faktor - faktor apa saja yang menjadi penyebab kerusakan produk. 


\section{Hasil dan Pembahasan Hasil dengan Check Sheet}

Tabel 3.1 Check Sheet Jumlah Produksi dan Produk Cacat UD. Ihtiar Jaya Tahun 2018

\begin{tabular}{|c|c|c|c|c|c|c|c|c|}
\hline \multirow[b]{2}{*}{ No } & \multirow[b]{2}{*}{ Bulan } & \multirow{2}{*}{$\begin{array}{l}\text { Jumlah } \\
\text { Produksi } \\
\text { (unit) }\end{array}$} & \multicolumn{4}{|c|}{ Jenis Cacat } & \multirow{2}{*}{$\begin{array}{c}\text { Jumlah } \\
\text { Produk } \\
\text { Cacat } \\
\text { (unik) }\end{array}$} & \multirow[b]{2}{*}{$\begin{array}{c}\text { Persentase } \\
\text { Produk } \\
\text { Cacat }\end{array}$} \\
\hline & & & Lecet & Penyok & $\begin{array}{c}\text { Tidak } \\
\text { Simetris }\end{array}$ & Belang & & \\
\hline 1 & Januari & 210 & 16 & 4 & 2 & 0 & 10 & $10.48 \%$ \\
\hline 2 & Februari & 76 & 5 & 2 & 2 & 1 & 12 & $13.16 \%$ \\
\hline 3 & Maret & 100 & 8 & 3 & 1 & 0 & 18 & $12.00 \%$ \\
\hline 4 & April & 364 & 11 & 5 & 1 & 1 & 10 & $4.95 \%$ \\
\hline 5 & Mei & 124 & 6 & 4 & 0 & 0 & 12 & $8.06 \%$ \\
\hline 6 & Juni & 94 & 4 & 4 & 2 & 2 & 16 & $12.77 \%$ \\
\hline 7 & Juli & 146 & 9 & 6 & 1 & 0 & 16 & $10.96 \%$ \\
\hline 8 & Agustus & 206 & 10 & 3 & 2 & 1 & 16 & $7.77 \%$ \\
\hline 9 & September & 166 & 11 & 3 & 1 & 1 & 10 & $9.64 \%$ \\
\hline 10 & Oktober & 106 & 7 & 2 & 1 & 0 & 12 & $9.43 \%$ \\
\hline 11 & November & 150 & 8 & 3 & 0 & 1 & 16 & $8.00 \%$ \\
\hline \multirow[t]{3}{*}{12} & Desember & 92 & 9 & 5 & 1 & 1 & 170 & $17.39 \%$ \\
\hline & Jumlah & 1834 & 104 & 44 & 14 & 8 & 14.17 & \\
\hline & & & 152.83 & 3.67 & 1.17 & 0.67 & 22 & $10.48 \%$ \\
\hline
\end{tabular}

Dari laporan check sheet diketahui bahwa selama tahun 2018, UD. Ihtiar Jaya memproduksi mebel sebanyak 1834 unit dengan jumlah produk mebel yang mengalami kecacatan sebanyak 170 unit. 170 unit yang cacat tersebut terdiri 104 cacat lecet, 44 cacat penyok, 14 cacat tidak simetris, dan 8 cacat belang.

Diagram Pareto : Berdasarkan diagram pareto dapat diketahui bahwa jenis cacat paling dominan pada produk mebel UD. Ihtiar Jaya tahun 2018 adalah lecet dengan persentase sebesar $61,18 \%$ sedangkan peringkat kedua adalah penyok dengan persentase sebesar $25,88 \%$ kemudian peringkat ketiga adalah tidak simetris dengan persentase sebesar $8,24 \%$ dan peringkat terakhir adalah belang dengan persentase sebesar $4,71 \%$. Sehingga dapat disimpulkan bahwa jenis cacat pada produk mebel yang menjadi prioritas utama untuk dilakukan perbaikan adalah jenis kecacatan berupa lecet.

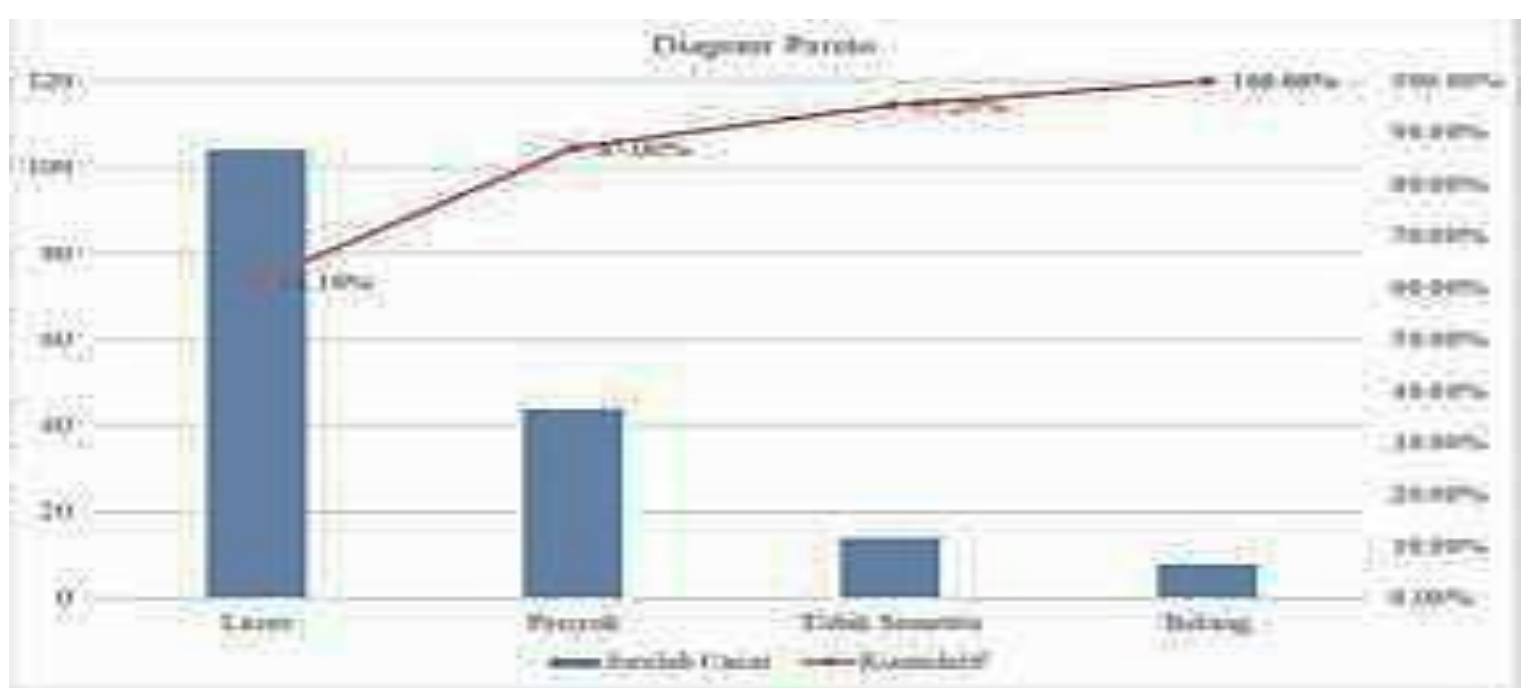

Gambar 1. Diagram Pareto Jenis Kecacatan Produk Mebel UD. Ihtiar Jaya tahun 2018 


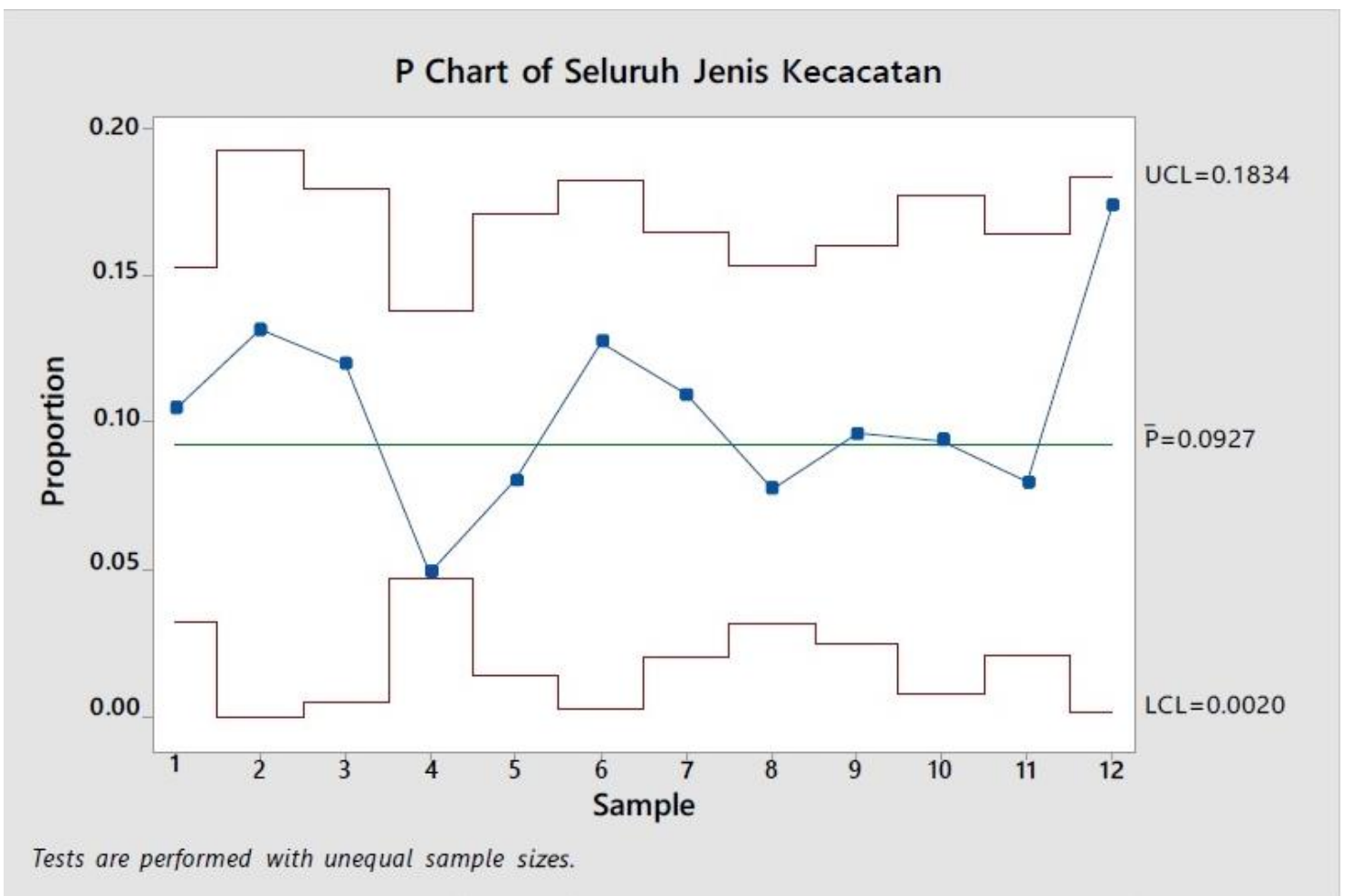

\section{Gambar 2. Peta Kendali P Produk Mebel}

Dari Gambar 2 memperlihatkan bahwa pada peta kendali $P$ untuk produk mebel UD. Ihtiar Jaya pada tahun 2018 yang mengalami kecacatan, baik cacat ringan maupun cacat berat dalam keadaan tidak terkendali, karena ada banyak titik yang berfluktuasi secara tajam dan tidak beraturan di luar batas garis CL. Bahkan ada satu titik yang menyentuh garis LCL. Titik tersebut ada pada bulan April.Sedangkan pada bulan Februari, Maret, Juni, dan Desember terjadi fluktuasi secara tajam dan tidak beraturan.Pengendalian kualitas yang baik ditunjukka $\mathrm{n}$ oleh proporsi cacat yang sejajar dengan garis CL. DiagramSebab-Akibat (Fishbone Diagram)

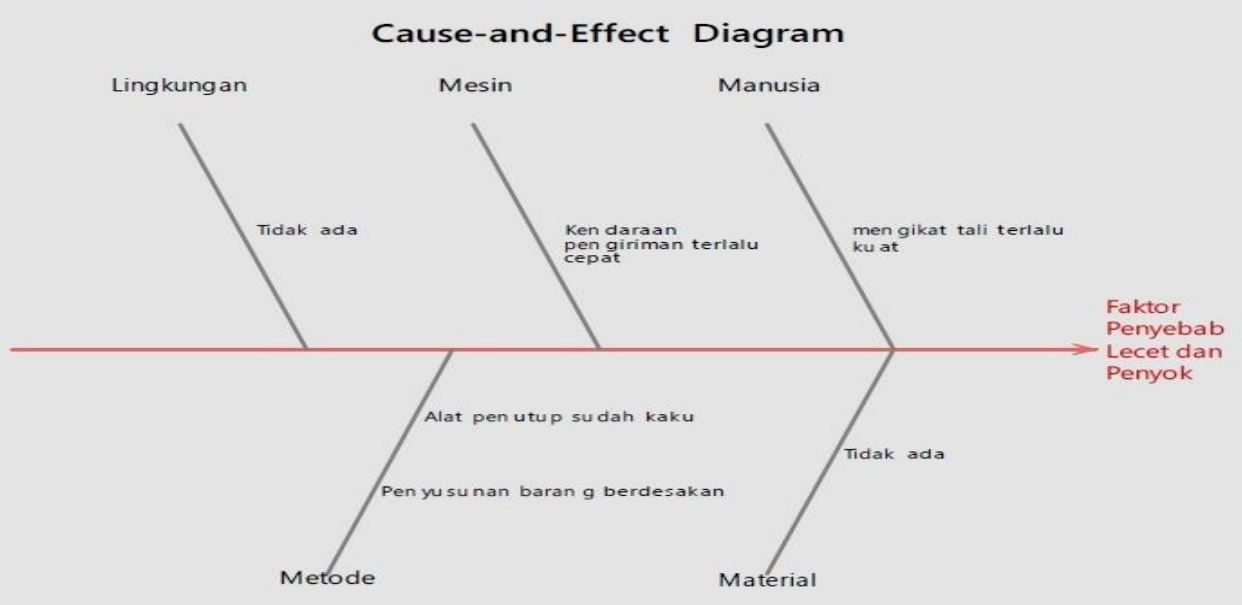

Gambar 3. Diagram Sebab-Akibat

Manusia. proses pengiriman dalam produk mebel tidak lepas dari proses bongkar muat barang. Penyebab produk mebel yang mengalami lecet maupun penyok dikarenakan proses bongkar muat. Para karyawan yang terlibat dalam proses ini sering mengikat tali terlalu kuat pada produk mebel. Material, material kayu maupun material lain yang 
digunakan dalam produksi mebel sudah sesuai dengan standar yang telah ditetapkan oleh perusahaan.Standar kayu yang telah ditetapkan oleh perusahaan yaitu mengenai ketebalan kayu dan kekeringan kayu yang digunakan. Mesin, Mesin yang berpotensi menimbulkan lecet dan penyok adalah kendaraan yang digunakan pada saat pengiriman.Kendaraan yang berjalan terlalu cepat pada saat pengiriman dapat mengakibatkan produk mebel yang diangkut menjadi lecet maupun penyok. Metode, Proses pengiriman merupakan proses yang menjadi penyebab produk mebel lecet maupun penyok.

Metode peletakan produk mebel yang akan dikirim ke kendaraan pengangkut terlalu berdesakan, sehingga apabila produk mebel saling bergesekan dan berbenturan maka produk mebel akan menjadi lecet maupun penyok. Penyebab produk mebel mengalami lecet maupun penyok yang lain saat proses pengiriman yaitu alat penutup yang sudah kaku. Saat proses pengiriman, produk mebel akan ditutup oleh terpal dan diikat oleh tali. Terpal yang kaku karena faktor usia akan berbeda dengan terpal yang masih baru. Terpal yang kaku tersebut bila bergesekan dengan produk mebel selama proses pengiriman akan menyebabkan lecet. Lingkungan, berdasarkan hasil wawancara dan observasi, tidak ditemukan lecet dan penyok yang disebabkan oleh faktor lingkungan. Lingkungan yang terlampau panas maupun dingin tidak akan berpengaruh pada kecacatan produk mebel berupa lecet maupun penyok.

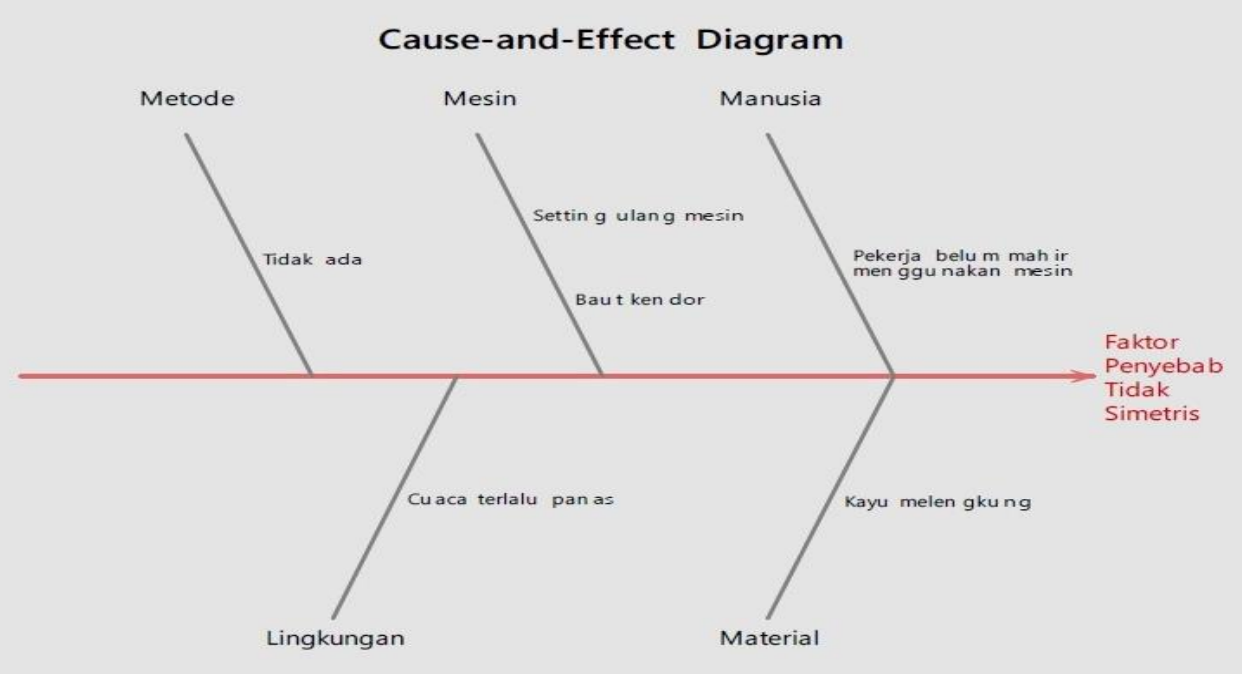

Gambar 4. Fishbone Diagram Produk Mebel Tidak Simetris

Manusia, salah satu penyebab kecacatan produk mebel adalah para pekerja atau karyawan yang belum benar-benar mahir dalam menggunakan mesin. Mesin yang dimaksud dalam pembahasan ini yaitu mesin tatah. Fungsi mesin adalah melubangi kayu untuk dijadikan sambungan antar kayu. Material, tegangan ijin kayu pada kayu jati dapat menyebabkan pergerakan kayu meskipun kayu sudah ditebang. Hal ini disebabkan karena proses penjemuran (oven kayu) yang kurang kering. Akibatnya pergerakan kayu masih tetap ada walaupun kayu tersebut sudah menjadi produk mebel. Fenomena ini dapat ditandai dengan melengkungnya kayu pada produk mebel yang sudah jadi, sehingga produk mebel menjadi tidak simetris. Mesin, berdasarkan hasil penelitian, baut yang ada dalam mesin tatah sering kendor. Hal ini menyebabkan mata pisau untuk melubangi kayu tidak bisa presisi sesuai dengan garis yang sudah didesain.Oleh sebab itu, maintenance mesin sangat perlu dilakukan untuk menimalisir kecacatan ini. Metode, berdasarkan hasil wawancara dan observasi, tidak ditemukan kecacatan mebel yang tidak simetris karena disebabkan oleh faktor metode. Lingkungan

Musim kemarau di Indonesia mempunyai suhu yang sangat panas. Kondisi cuaca yang terlampau panas saat proses produksi mengakibatkan pemuaian pada kayu. Hal ini menyebabkan produk mebel bisa menjadi tidak simetris dikarenakan ukuran kayu yang telah berubah karena proses pemuaian. 


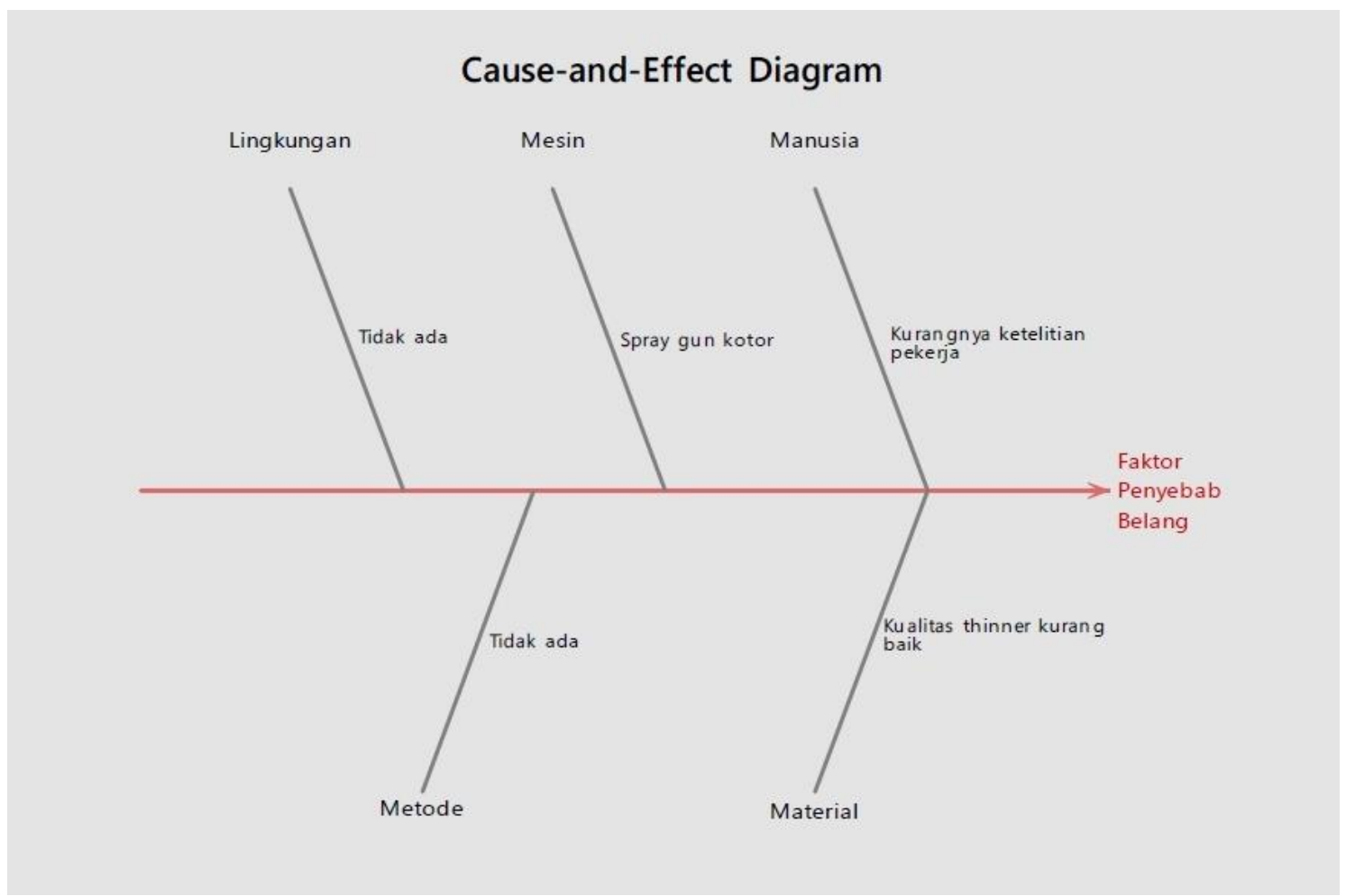

\section{Gambar 5. Fishbone Diagram Produk Mebel Belang}

Kecacatan ini sering terjadi saat proses pengecatan menggunakan spray gun oleh karyawan bagian finishing. Jika bagian mebel yang dispray lebih tebal dari bagian yang lain maka kecacatan belang akan terjadi, Material, faktor material dalam kecacatan produk mebel berwarna belang terletak pada material bernama thinner. Apabila thinner yang dipakai tidak cocok dengan takaran dan kualitas yang dibutuhkan oleh cat, maka akan berdampak pada belangnya warna yang akan dihasilkan. Mesin,faktor penyebab kecacatan produk mebel yang berwarna belang ada pada mesi $\mathrm{n}$ spray gun. Kondisi spray gun yang tidak baikakan mempengaruhi hasil pengecatan. Uj ung spray gun (nozzle) yang tidak dibersihkansetelah digunakan akan menyebabkan hasil spray yang tidak beraturan. Metode, berdasarkan hasil penelitian, tidak ditemukan kecacatan mebel berwarna belang karena disebabkan oleh faktor metode. Lingkungan, berdasarkan hasil wawancara dan observasi, tidak ditemukan warna belang yang disebabkan oleh faktor lingkungan.

\section{Simpulan dan Saran}

Dari hasil check sheet dapat dilihat bahwaselama tahun 2018 perusahaan memproduksi mebel sebanyak 1834 uni t dengan jumlah produk mebel yang mengalami kecacatan sebanyak 170 unit. Hasil diagram pareto yang telah dibuat, tingkat kerusakan/kecacatan yang paling tinggi adalah cacat berupa lecet. Dari hasil grafik peta kendali $\mathrm{P}$ ( $P$-chart) yang telah dibuat dapat dilihat bahwa pengendalian kualitas dalam kondisi yang tidak terkendali dan belum sesuai dengan standar. Dari hasil analisis fishbone diagram dapat diketahui faktor penyebab kecacatan dalam produksi mebel, yaitu berasal dari faktor pekerja, mesin produksi, metode kerja, material/bahan baku dan lingkungan kerja. saran yang saya dapat berikan adalah: Bagi perusahaan, sebaiknya meningkatkan kemampuan pengendalian kualitas produk mebel berdasarkan hasil Statistical Process Control dan melakukan tindakan pencegahan sesuai saran dari peneliti ataupun kebijakan lain dari perusahaan berdasarkan faktor - faktor penyebab kecacatan yang telah ditemukan agar reject produksi tidakmenyebabkan kerugian terhadap perusahaan di masa yang akan datang dan mengurangi produk yang cacat pada produksi berikutnya. Bagi peneliti selanjutnya, disarankan untuk mengembangkan penelitian dengan menggunakan metode 
perhitungan pengendalian kualitas yang lain agar memperoleh hasil lebih akurat guna meningkatkan pengendalian kualitas secara lebih baik.

\section{Daftar Pustaka}

Besterfield, Dale H. 2013. Quality Improvement (9th edition). New Jersey: Pearson Prestice Hall.

Elmas, Muhammad Syarif Hidayatullah. 2016. "Pengaruh Bauran Pemasaran dan Kualitas Produk Meubel di UD. Sekawan Rimba Wangkal Gading Kabupaten Prbolinggo". Jurnal Pendidikan Ekonomi. Hal. 138.

Gasperz, Vincent. 2010. Total Quality Management. Jakarta: PT. Gramedia Pustaka Utama.

Gitosudarmo, Indriyo. 2014. Manajemen Operasi. Yogyakarta: BPFE.

Handoko, T. Hani. 2012. Dasar-Dasar Manajemen Produksi dan Operasi. Yogyakarta: BPFE.

Heizer, Jay dan Render, Barry. 2015. Manajemen Operasi. Edisi 11. Jakarta: Salemba Empat.

Montgomery, Douglas C. 2012. Introduction to Statistical Quality Control.7th Edition. New York: John Wiley \& Sons, Inc.

Nasution, M. N. 2010. Manajemen Mutu Terpadu. Bogor: Ghalia Indah.

Salim, Zamroni dan Munadi, Enawati. 2017. Info Komoditi Furnitur. Jakarta: Badan Pengkajian dan Pengembangan Perdagangan Kementrian Perdagangan Republik Indonesia.

Sugiyono. 2015. Metode Penelitian Bisnis. Bandung: CV. Alfabeta.

Sugiyono. 2015. Metode Penelitian Kombinasi (Mix Methods). Bandung: CV. Alphabeta.

Trenggonowati, Dyah Lintang dan Arafiany, Nur'aini Minati. 2018. "Pengendalian Kualitas Produk Baja Tulangan Sirip 25 Dengan Menggunakan Metode SPC Di PT. Krakatau Wajatama Tbk". Journal Industrial Servicess. Vol. 3 No. 2.

Yamit, Zulian. 2013. Manajemen Kualitas Produk \& Jasa. Yogyakarta: Ekonisia. 